\title{
HISTOPATHOLOGY OF BRAIN ABSCESS
}

\author{
WITH REMARKS ON INTRASPINAL THERAPY *
}

\author{
GEORGE B. HASSIN, M.D. \\ Attending Neurologist, Cook County Hospital \\ CHICAGO
}

The pathologic changes in brain abscess are, as a rule, so manifest, even on macroscopic examination, that a correct diagnosis offers practically no difficulty, however insignificant the abscess may be. Probably this is the main reason for the scarcity of literature on microscopic brain changes resulting from abscess. Yet studies of the histo'ogic changes are of great scientific interest, for they may clear up some as yet unsettled questions which are not only of academic, but also of practical, value.

Brain abscess perhaps brings to mind a circumscribed lesion more or less walled off by a membrane. Since time is required for a membrane to form, the walling off of an abscess necessarily must be a more or less gradual, subacute or chronic process that ultimately leads to transformation of a portion of brain tissue into a cavity filled with pus. This gradual replacing of the brain tissue by a walled off, encapsulated cavity is lacking in acute suppurative brain lesions. In these the suppurative process is rather diffuse, producing pronounced and extensive changes in the ganglion cells, glia tissue, nerve fibers and even in the vessels themselves.

MICROSCOPIC STUDY OF LESIONS OF BRAIN ABSCESS

Photomicrograph 1 (Fig. 1) gives some idea of widespread destruction. It represents a section of the brain cortex from a patient with a septic purulent meningitis secondary to an acute otitic abscess which ruptured into the brain, causing the patient's death on the twelfth day. The structure of the brain is totally changed. Instead of the regular layers of ganglion cells, there is a mass of strange elements which under low power can hardly be defined. Only blood vessels with somewhat thickened infiltrated walls and narrowed, thrombosed lumen, scattered fibrin fibers, erythrocytes and pus cells can be made out. Under a high power, there can be discerned fragments of somewhat changed nerve fibers, glia cells in a condition of ameboid degeneration and scattered hemorrhagic foci. Areas not directly affected by the pus invasion are much better preserved, though microscopically quite changed. In

\footnotetext{
* From the pathological lahoratories of Cook County and Psychopathic Hospitals, Chicago.
} 
these areas the blood-vessels exhibit dilated perivascular spaces infiltrated with lymphocytes and plasma cells, while the ganglion cells are either in a state of mild chromatolysis or so-called cloudy swelling, or altogether normal. In short, such spaces exhilit parenchymatous and interstitial changes typical of acute nonsuppurative encephalitis. These are the reactions of brain tissue in diffuse suppuration which has not had sufficient time to become encapsulated and which leads to total destruction of some elements (ganglion cells), partial destruction of

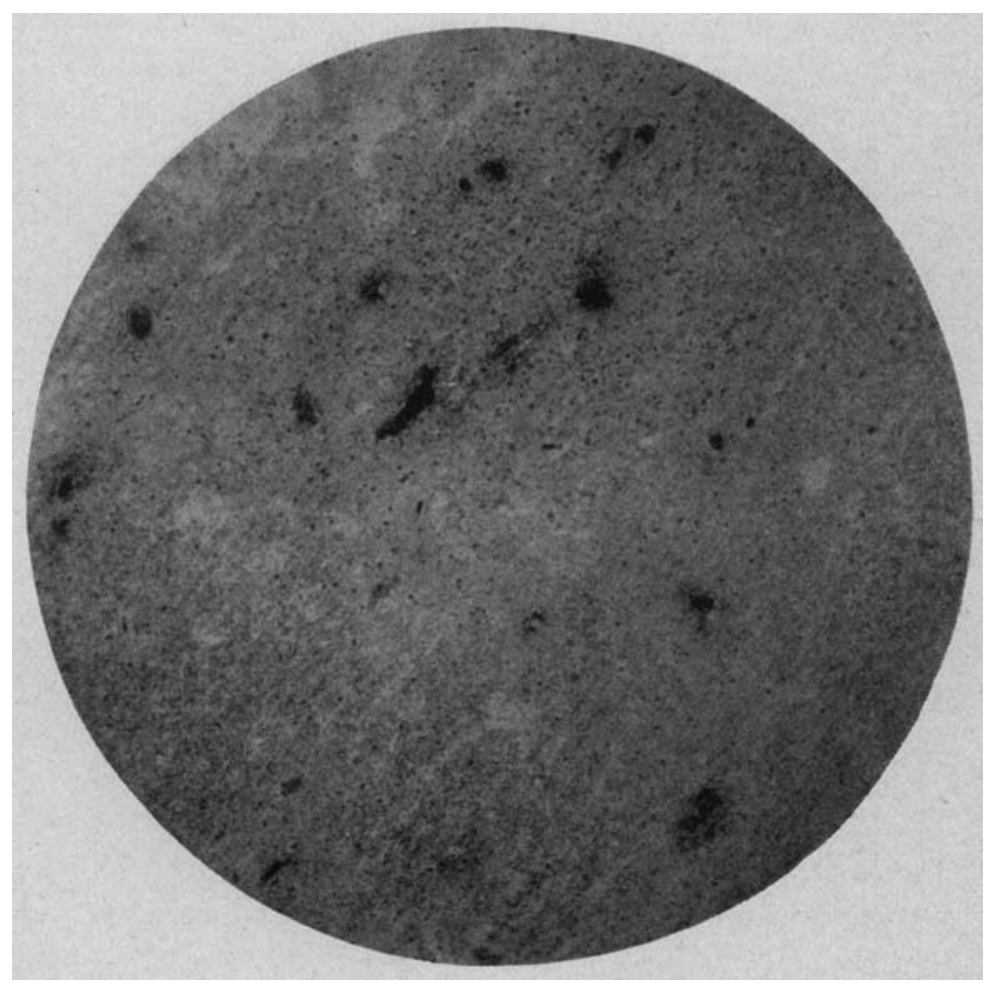

Fig. 1.-Brain section from a case of acute otitic alscess that ruptured into the brain killing the patient on the twelfth day of his illness. The black spots are ressels, thromlosed and with thickened walls, surrounded in some places by fibrin filers. The numerous dots are glia nuclei. (Frozen section. Alzheimer-Mam stain, $\times 75$.)

others (nerve fibers, glia cells) and progresive vascular changes (hyperenia, thickening and infiltration of the vasular walls, new formation of capillaries, etc.).

Source of Connectio' Tissue in Brain Tissut.- l'erhalls of greater interest are the findings in cases of encapsulated alscess. The capsule of an old abscess maty be incredibly thick. For instance, in one of Bascoe's cases of eight years' duration, demonstrated before the Chi- 
cago Neurological society, the thickness was one quarter of an inch, very dense and fibrous, much resembling the dura. In fact. the first impresion gained from a superficial examination was that the membrane was an outgrowth from the dura. Thus we are confronted by a peculiar phenomenon: growth of a large mass of hard connective tissue in brain tissue, where under normal conditions, connective tissue is solely confined to ressels and the tender prolongations of the pia. Naturally, it is desirable to determine how and from where such an

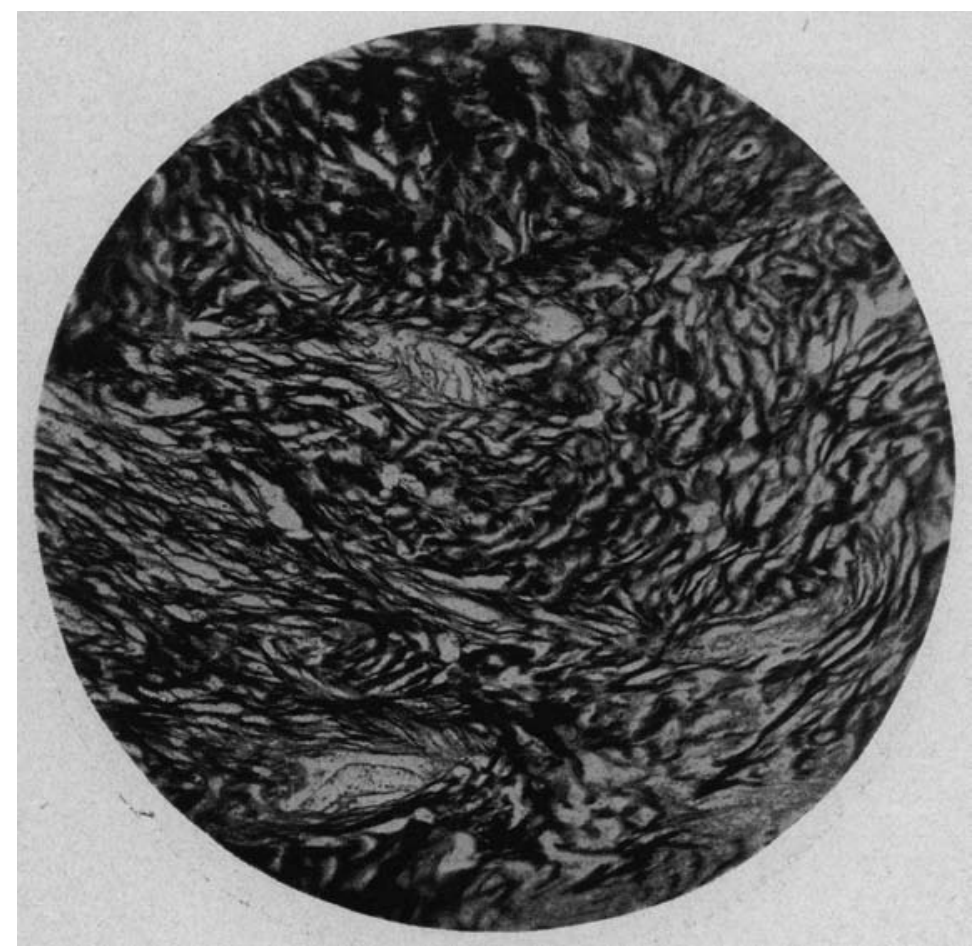

Hig. 2.-A surface (longitulinal) section of the inner layer of the capsule, eight years old. The comective tissue fibers crossing and intercrossing each other form dense meshes with narrow interspaces enclosing a few cellular elements: there is a total lack of blood vessels. The entire structure very much resembles a fibrous scar tissue. (Combined Bielschowsky-AloheimerMann stain. Paraffin section, $\times+5$.)

abnormal. unusual and excessive amount of connective tissue growth develops. This problem I have tried to solve.' The study of my material (young membranes) apparently demonstrated that the growth of connective tisisue arose exclusively from the blood elements, the lymphocytes, which by gradual and progressive transformation turned

1. Hassin. G. B.: Histolathologic Studies on Brain Abscesses. Med. Rec. 93:91 (Jan. 19) 1918. 
into fibrobiasts, and then into connective tissue fibers, finally to become a solid membrane.

Through the kindness of Dr. Peter Bassoe. I have had the opportunity of studying much older abscess membranes. ()ne, about eight years old, enveloped a large abscess that resulted from a bullet lodged in the brain. In three other cases the membranes were comparatively younger, but their macroscopic and microscopic aspects were much alike. The membranes, as well as various portions of the brain and

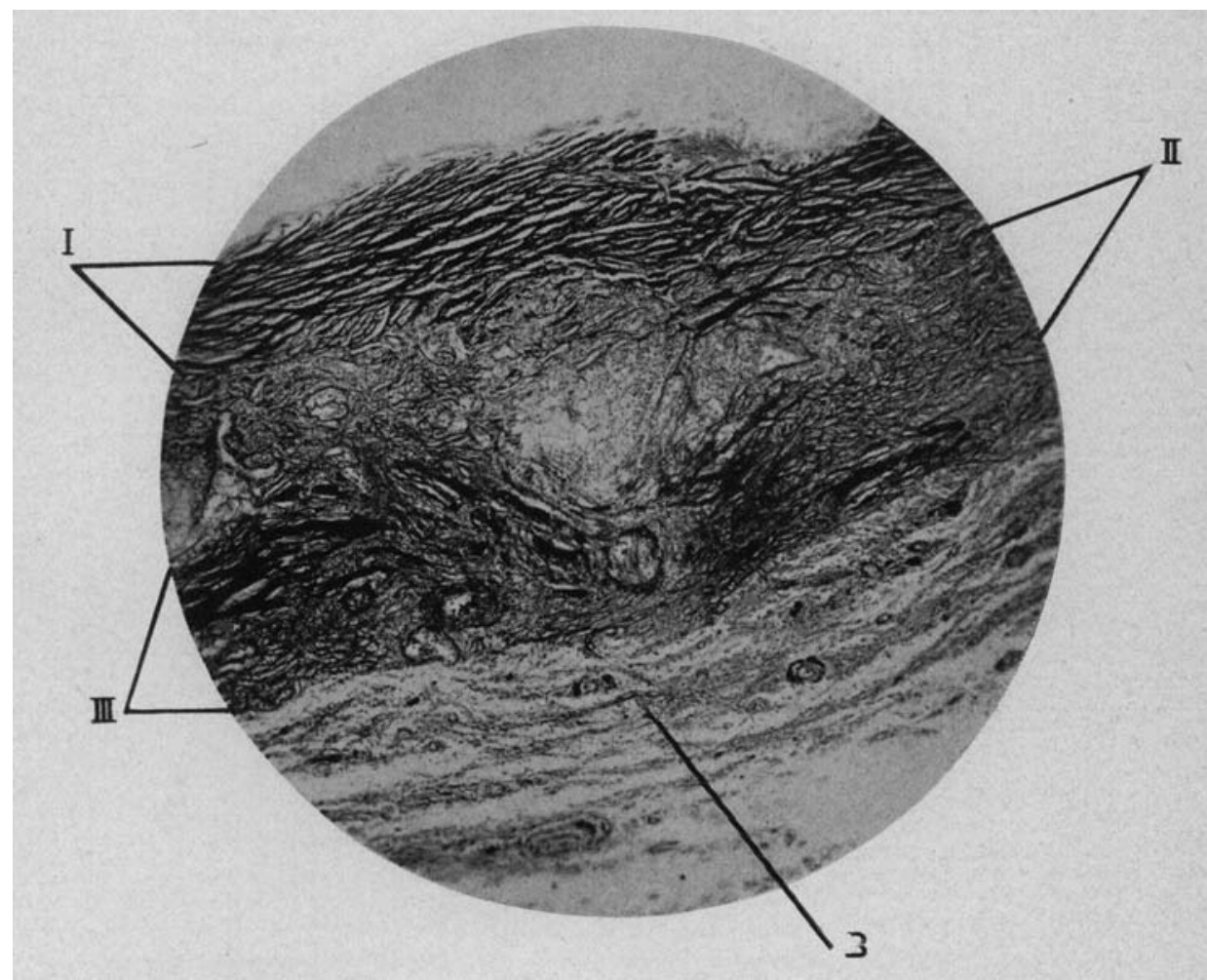

Fig. 3--Transverse section of the eight year old capsule. The external layer (III) consists, like the inner one, of connective tissue but shows a number of vessels that are absent in the internal layer (I). II-the middle layer also reproduced on a surface section on the photomicrograph. IV-B, brain tissue shows numerous small vessels infiltrated with fat. (Stain same as in Figure $2, \times 45$.)

cerebellum, have been studied on celloidin, paraffin, and frozen sections with various staining methods. The capsules were examined in transverse and longitudinal or surface sections, the respective layers having been taken up separately. The inner layer (Fig. 2) directly surrounding the abscess presents a mass of collagen, powerful fibers crossing and intercrossing, forming an irregular network containing 
numerous interspaces. The latter usually enclose a few cellular elements. or rather remnants of arious cells which cannot be well defined. They mostly appear shrumken, some being cystic and vacuolated, some oblong and flattened, with a very pale, hardly visible nutclens. Few of them show the presence of fat. Blood ressels in this layer are lacking. as well as polymorphonuclear cells, pus cells, fibroblasts or other inflammatory elements. Somewhat similar in structure is the external layer (Fig. 3). It also contains a wealth of collagen fibers, which, though

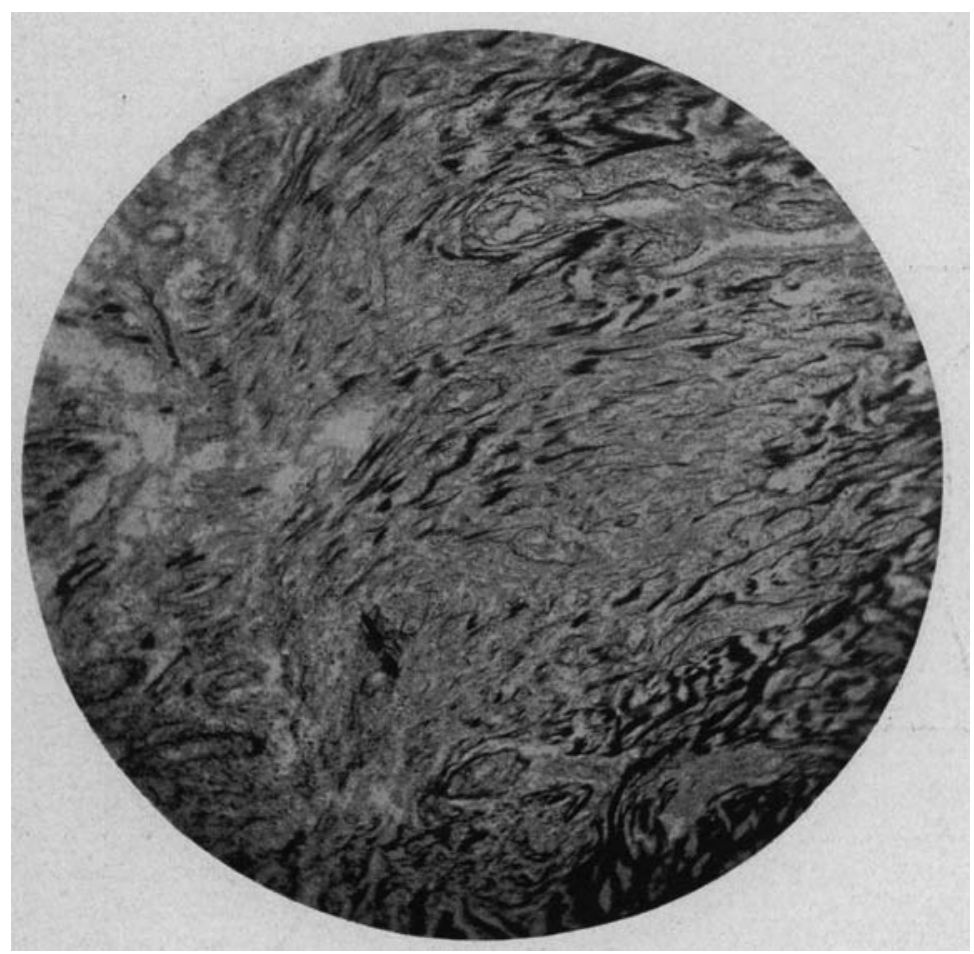

Fig. 4.--Surface section of the middle layer of the eight year old capsule. The predominance of ressels and cellular elements (in the pale areas) is quite marked. (Stain and magnification the same as in Figures 2 and 3.)

somewhat less thick, equally form dense meshes packed with an enormous amount of cellular elements (plasma cells, gitter cells, fibroblasts and some lymphocytes). Vessels here are more numerous, their adventitial spaces are dilated, but blood cells, pus elements, polymorphonuclear cells and signs of inflammation are totally lacking. Between these two membranes there can be discerned (Figs. 3 and 4) the third layer which shows a wealth of cellular elements and vessels. This membrane also contains connective tissue fibers, but these are much more tender and delicate than those of the external and internal layers. 
In some places it consists solely of a great mass of fat grantule bodies which, with Herxheimer scarlet red stain, appear (Fig. 5) as black masses. Being comparatively poorer in collagen fibers and richer in blood ressels and cellular elements (plasma cells, fibroblasts), this membrane is evidently less organized, and therefore less powerful than the outer and inner layers. The difference of structure in the three layers making up the abscess capsule can be seen from a glance at Figure 3 which represents a transverse section of the calsule. The

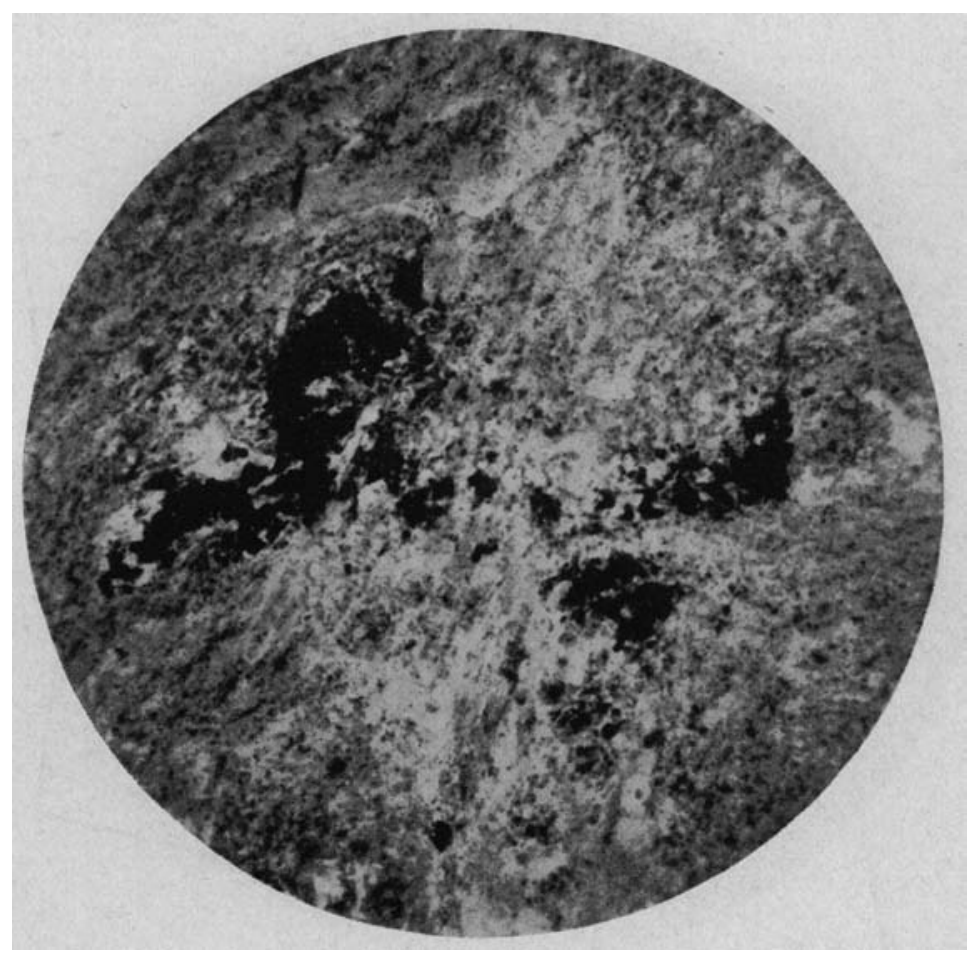

lig. 5.-Surface frozen section of the middle layer of Figure 3 shows vast accumulations of fat as black masses. (Herxheimer scarlet red stain, $X 100$.)

inner and outer layers, similar in structure, are separated by a paler zone rich in gitter cells and blood ressels. The first two appear like a scar. while in the middle the scar formation is hardly advanced. The cicatrization apparently is obtained in those zones where it is most needed: first, in the surface next to the abscess to hold it in check and, second, on the border of the brain substance to prevent its contamination, or invasion by pus. These three layers in a capsule can be still more easily distinguished in a case of but a few months' duration. The membrane in this case (Fig. 6) also shows a powerful inner layer, 
a less powerful, though fully developed external layer and a midile layer rich in vessels and cellular elements.

Comparing Fignres 3 and 6 one can casily see the difference between these two capsules: the former (Fig. 3) is almost totally organized, while the latter is but partially so. llad the patient in the latter case lived longer, the cansule would undoubtedly have assumed the features

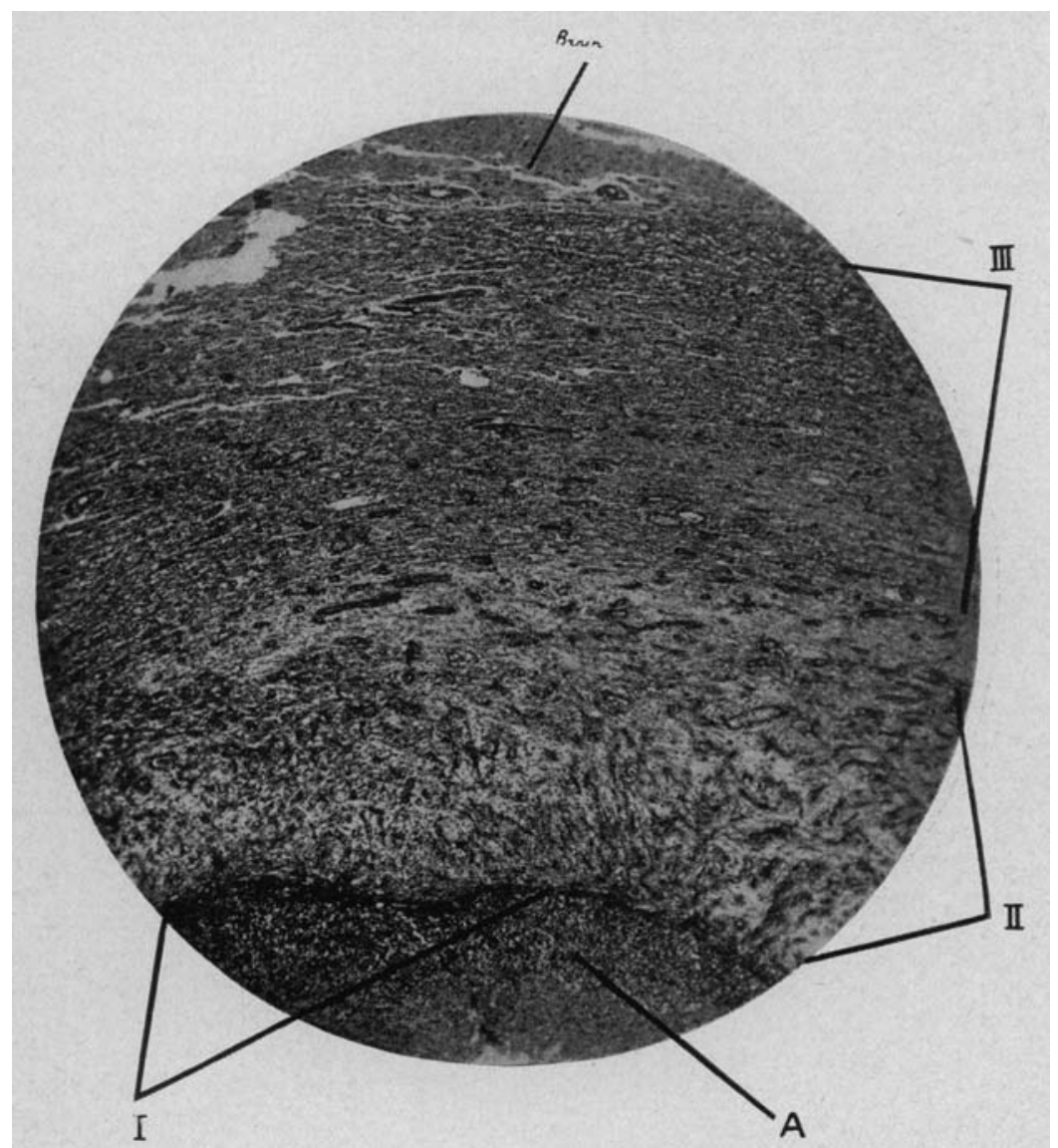

Fig. 6.-Transterse section of the younger calsule fsereral months old) I. II. III, respective layers: A, the alsscess. The lup tif the picture represents a practically normal brain tissue with several iniltrated ressels. Like the much older capsule reproduced in Figure 2, it shows the identical organization of the inner (I) and external (III) layers: while the midlle (Il) layer, rich in ressels, is less organized. (Van Giesen stain. $\times 30$.

of the one in the former case. Whether young or old, once organized, the capsule surrounding the abscess forms an excellent protection for the brain tissue. which is wholly preserved (Figs. 6. 7 and 8). It exhibits no pathologic changes in the ganglions, glia cells or nerve 
fibers, but the ressels and the piatarachnoid are decidedly altered. While the lumen of a vessel, its intima and the middle layers are normal, the adrentitia with its space (Virchow-Robin) is enormously developed (Fig. 9) and made up of numerous bands of connective tissue fibers with narrow interspaces packed with plasma cells. The latter can lue easily recognized in the photomicrograph (Fig. 9). espe-

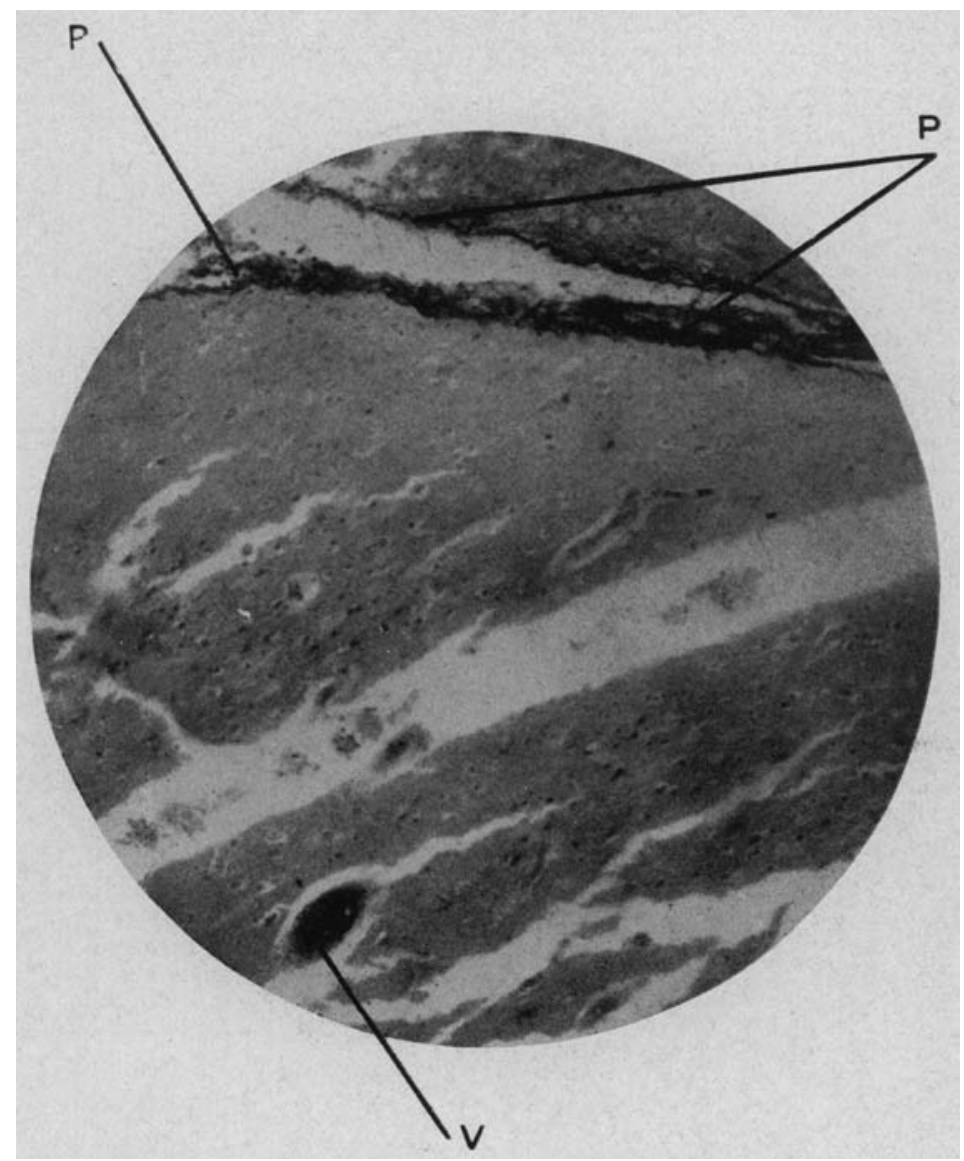

Fig. 7.-Between the much infiltrated blood ressel (V) and the pia (P) (especially its lower hranch) is situated an apparently normal brain tissue. The infiltration elements are mostly fat granule bodies and other elements reproduced in Figures 8 and 10 . (Bielchwsky-Alzheimer-Mann stain, $X 100$.)

cially with the help of a hand lens. Aside from plasma cells and their modifications, young fibroblasts, there are also present gitter cells filled with fat globules. Numerous in the external portions of the adventitia, the cellular elements are scarce in the inner portions, where they are replaced by collagenous fibers, which totally fill up the distended adventitial spaces (Fig. 9). In short, the adventitia is in a hyperplastic state 
surrounding the vessels like a muff and invariably containing fat. It represents an extinct inflammatory condition which ultimately resulted in the formation of a fibrous ring around the vessel.

Far removed from such a vessel (Figs. 7 and 8 ), and separated from it by normal brain tissue, is the pia arachnoid. At the first glance this appears to be infiltrated in some places. However, closer examination (Fig. 8) shows that the infiltration did not involve the

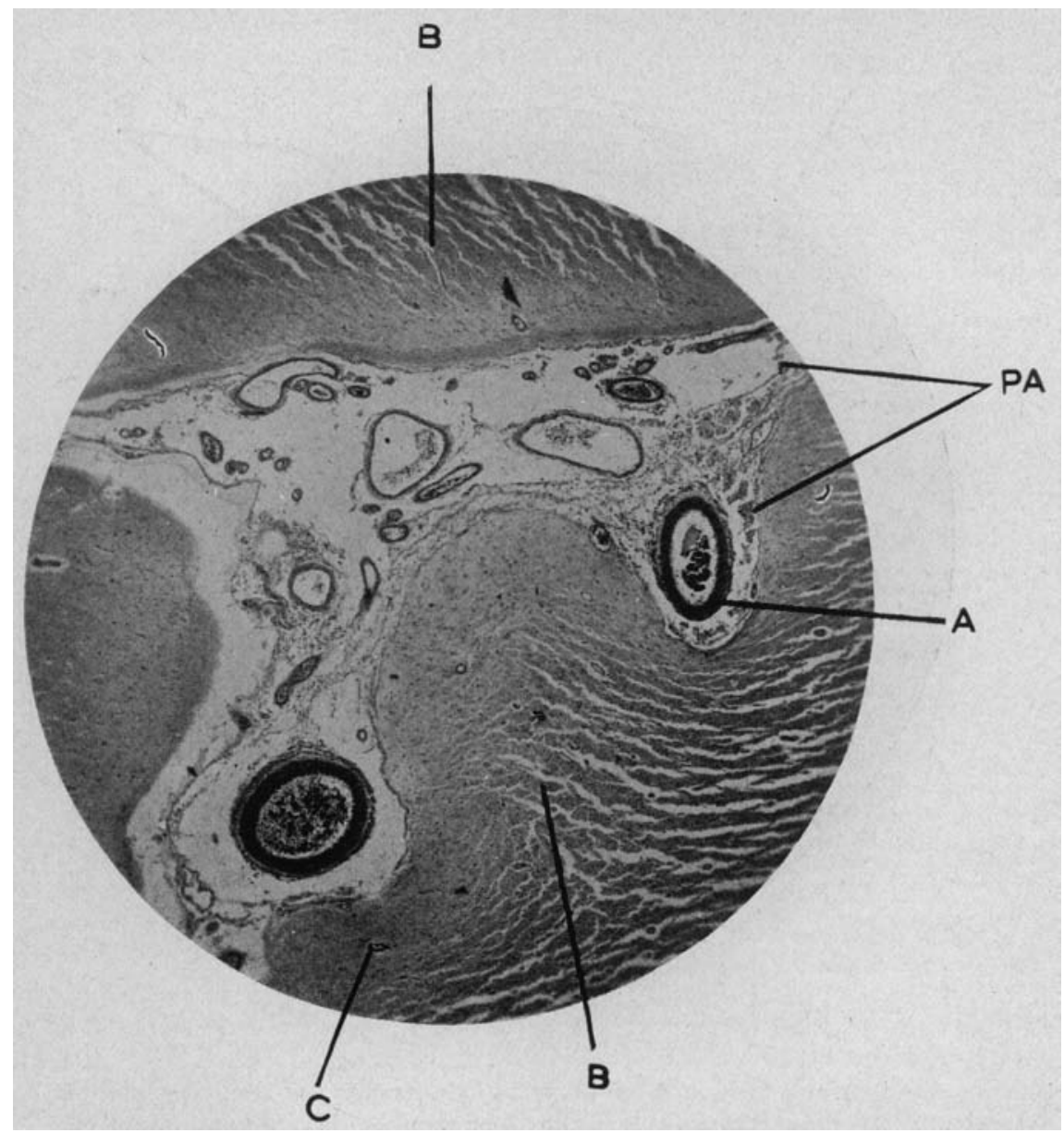

Fig. 8.-P A, pia arachnoid, showing the dilated and infiltrated subarachnoid space as well as numerous vessels; A, artery with an infiltrated adventitial space; B, brain tissue without any changes, except minute capillaries slightly infiltrated with fat. $C$, infiltrated capillary. Use hand lens. (Same stain as in Figure $7, \times 33$.)

pia at all, this membrane being normal. The infiltration is rather confined to the distended subarachnoid space as well as to the numerous vessels. The infiltration elements are partly lymphocytes, but mostly macrophages and gitter cells (Fig. 10). The macrophages and gitter 
cells are very large, the former enclosing various debris of lymphocytes, nuclei, etc, while tine gitter cells are packed with lipoid, or fatlike substances. Erident signs of inflammation, hemorrhages, fibroblasts, plasma cells. etc., are lacking in the pia-arachnoid. The lipoid substances, as well as cell remmants. enclosed within the macrophages thus can be located in the subarachnoid spaces even when they are widely separated from the abscess and its capsule. The probability is strong that these lipoid substances came into the subarachnoid space from the capsule, its ressels and their perivascular spaces. In other words, it is nost probable that the fat found in such abundance in the

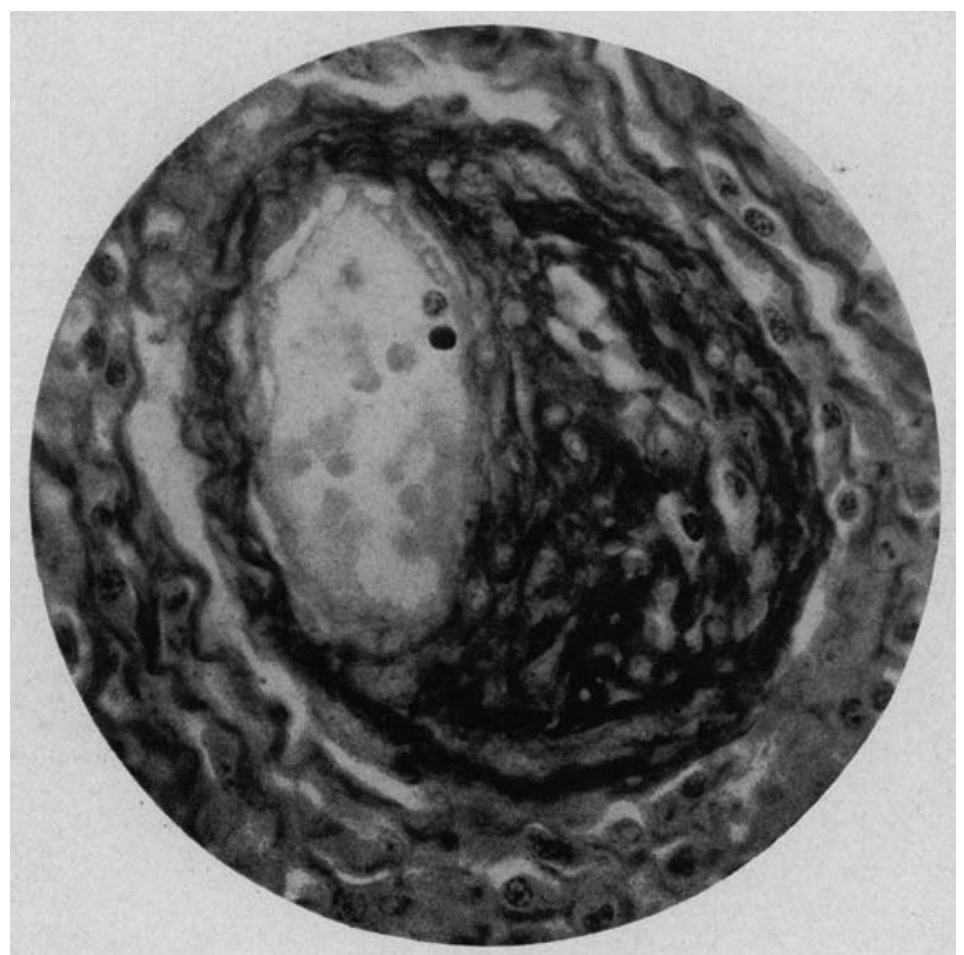

Fig. 9.-Transverse section of a blood vessel (vein) from the vicinity of a capsule of an eight year old brain alsscess. The patent lumen shows red cells and two lymphocytes; the adventitial, greatly dilated, space exhibits a vast amount of connective tissue fibers resembling a scar and containing in the interspaces numerous plasma cells, especially in the external areas. Many plasma cells are assuming the shape of fibroblasts. L'se a hand lens. (Same stain as in Figure $7, \times 600$.)

capsule reached the subarachnoid space by way of the perivascular spaces or-which is the same thing-that the contents of the perivascular spaces were emptied and discharged into the subarachnoid cerebral space. In no other way could the presence in the latter of gitter cells, macrophages and lymphocytes be exp'ained. as a normal pia-arachnoid is totally deroid of stuch elements. 


\section{DIRECTION OF FLOW OF BRAIN TISSCEE FLUIDS}

But to enable pathologic elements to reach the subarachnoid space from the depths of the brain tissue, there must be some pathway leading from the latter to the former; this pathway is composed of the perivascular spaces of Virchow-Robin. That they form such a connecting link is generally admitted. and Weed," by his remarkable experimental work, conclusively proved that the fiow of the perivas-

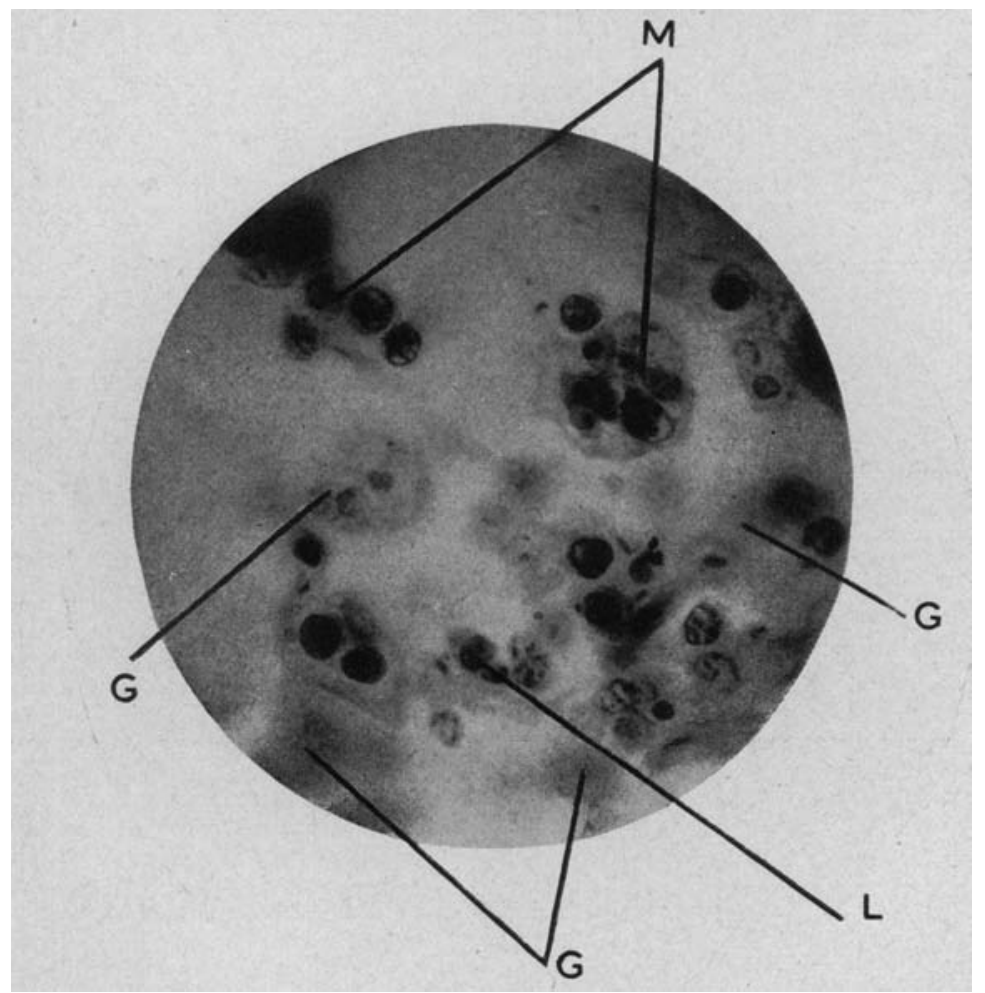

Fig. 10.-Types of intiltration cells in the subarachnoid space reproduced in Figure 8. M, macrophages; G G, Gitter cells; L. lymphocytes. (Same stain as in Figure $7, \times 1200$.)

cular contents is from the brain to the subarachnoid space. For his experiments Weed used 1 per cent. solution of equal amounts of iron

2. Weed, L. H.: Studies on Cerelorospinal Fluid. II. The Theories of Drainage of Cerebrospinal Fluid with an Analysis of the Methods of Investigation, J. Med. Res. 26:21, 1914-1915. III. The Pathways of Escape from the Subarachnoid Spaces with Particular Reference to the Arachnoid Villi, Ibid. 26:51, 1914-1915; IV. The Dual Source of Cerebrospinal Fluid, Ibid. 26:93. 1914-1915; An Anatomical Consideration on Cerelorospinal Fluid, Anat. Rec. 12:461 (May) 1917-1918. 
ammonium citrate and potassium ferrocyanid. This fluid, isotonic with the body fluids, was injected under long continued pressure of from 130 to $180 \mathrm{~mm}$. of water, into the lower thoracic and upper lumbar regions, or into the arachnoid cistern about the cerebellum of cats and dogs. After the injection was completed the head of the animal was severed from the body and placed in a 40 per cent. solution of formaldehyd to which a from 1 to 5 per cent. solution of hydrochloric acid was added. The resulting precipitate of ferric ferrocyanid in the form of bluish granules (Prussian blue) could easily be identified wherever the fluid had been absorbed. The course of the absorption of the injected solution can be assumed, as Weed rightly concluded, to be the true pathway normally pursued in the absorption of the cerebrospinal fluid, as the results are obtained with nontoxic solutions practically isotonic with the body fluids. These pathways, as indicated by the deposits of the Prussian blue granules, prove to be the pial meshes, the subarachnoid space, the dural spaces, the pacchionian bodies and the sinuses (longitudinal, cavernous) as well as the perineural spaces of some cerebral nerves, diploe ressels and lymph channels (outside of the cranium, but none in the brain tissue proper). Practically the same pathways could be traced in a case of metastatic carcinoma of the cerebral meninges ${ }^{3}$ in which, as in Weed's experiments, their invasion by carcinomatous cells was not accompanied by that of the brain. Only by using high pressure in his injections, did Weed succeed in finding the Prussian blue grantes in the adventitial spaces of the brain vessels.

These experimental and pathologic facts apparently prove that the brain substance, under normal conditions, does not obtain anything from the subarachnoid space whatever its content may be-Prussian blue, cancer cells or a solution of arsphenamin. This contention is supported by Figure 11, a photomicrograph from a case of cerebrospinal meningitis. The pia is greatly infiltrated by plasma cells, the subarachnoid space is distended and separated from the arachnoid by a mass of pus cells, while the cerebellar tissue does not show a single pus cell, plasma cell or any other kind of abnormality. In some way the plasma and pia cells are kept, as it were, from penetrating into the cerebellar substance. This would not be the case had the flow been from the meningeal spaces toward the cerebral or cerebellar substance.

While this finding. together with the above mentioned results of Weed's work, seem to prove that the cerebrospinal fluid or the content of the subarachnoid space does not flow toward the brain, there are comparatively few and less convincing facts tending to show that the

3. Hassin, G. B.: Histopathology of Carcinoma of the Cerebral Meninges, Arch. Neurol. \& Psychiat. 1:705 (June) 1919. 
current of the brain tissue fluids is toward the subarachnoid space and away from the brain. These brain tissue fluids are normally present in the adventitial or perivascular spaces of Virchow-Robin, which spaces it is generally admitted, are connected with the subarachnoid space, the container of the cerebrospinal fluid. Spina's, ${ }^{4}$ Foerster's " and Weed's ${ }^{2}$ experiment's brought out some striling evidence in favor

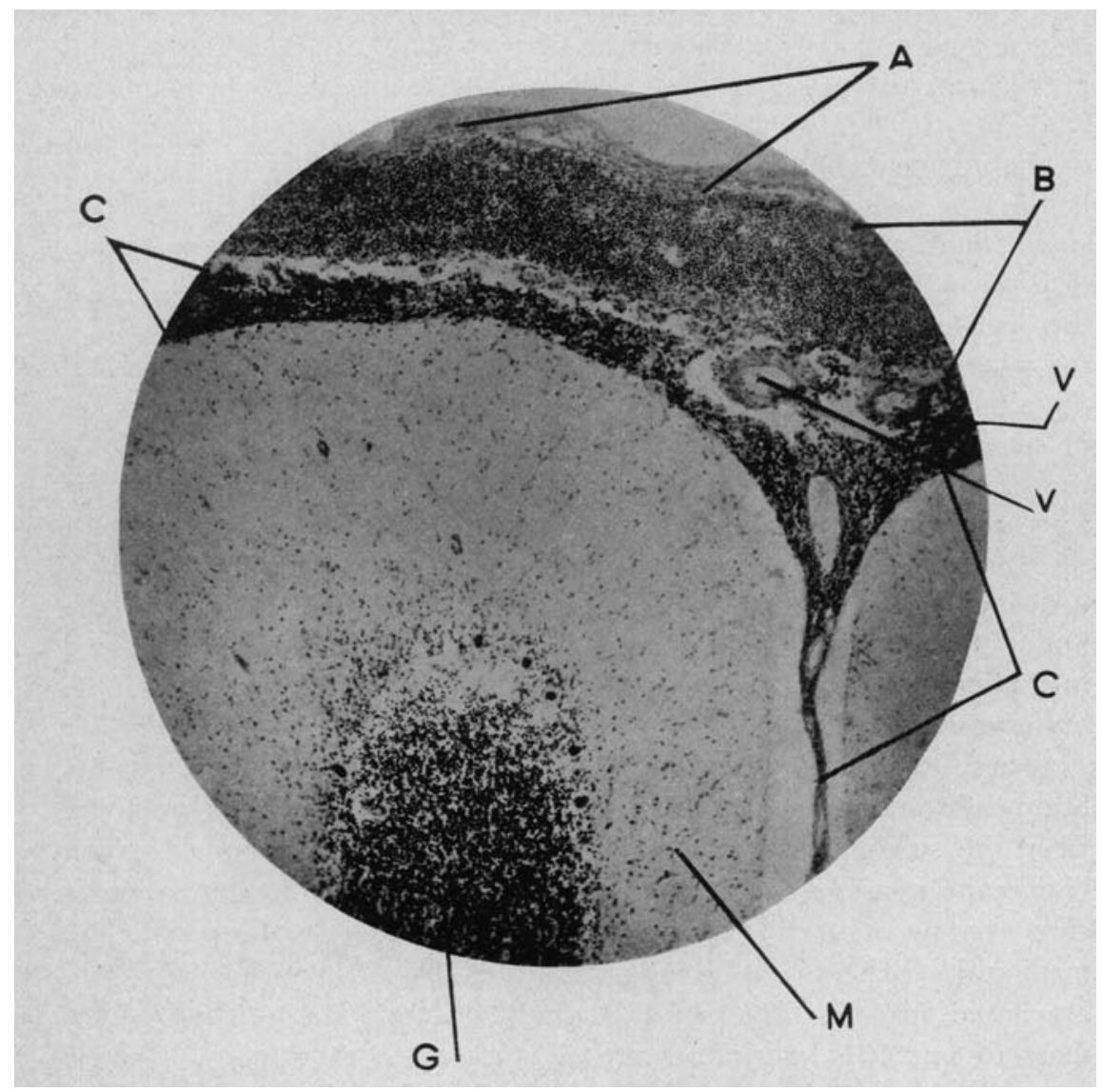

Fig. 11.-Pia arachmoid and subarachnoid space from a case of cerebrospinal meningitis. A, arachnoid; B, subarachnoid space packed with pus cells; C. pia infiltrated with plasma and mesothelial cells; $V \mathrm{~V}$, blood vessels of the pia with an infiltrated adventitia; $M$, molecular layer of the cerebellum. free from any foreign elements; $G$, granular layer of cerebellum surrounded by Purkinje cells. The molecular layer (M) shows two prominent capillaries with densely stained endothelial cells. (Toluidin blue stain, $\times 60$.)

4. Spina, A.: Experimentelle Untersuchungen über die Bildung des Liquor Cerebrospinalis. Arch. f. d. ges. Physiol. 76:204, 1899.

5. Foerster. E.: Experimentelle Beiträge zur Lehre der Phagocytose der Hirnrindenelemente, Nissl's Arlueiten 11:173, 1908. 
of the opinion that the current is from the adventitial spaces toward the subarachnoid space. Spina found beads of fluid on the surface of the cerebrum after he had produced increase of pressure in the brain. Foerster found india ink granules in the subarachnoid space after injecting sterile india ink solution into the cerebral substance, and Weed, as already noted, found granules in the brain vessels when he made injections under high pressure. The pathologic findings in brain abscess conclusively show, in my opinion, the correctness of the view of the foregoing investigators that the flow is from the adventitial spaces of the brain toward the subarachnoid space. The enormous masses of fat in the capsule, as shown in Figure 5, are discharged or transported to the subarachnoid space by the way of the perivascular spaces of the cerebral vessels. The fat substance in the subarachnoid space could not reach it in any other way. Neither could the presence of fat in the perivascular spaces of the cerebral blood vessels themselves be explained, unless it came from its source of supply - the abscess and its capsule. This outward flow of brain tissue fluid seems to me to be but a natural and unavoidable process. The waste of the activity of the brain elements must be removed in some manner, and as the central nervous system lacks lymphatics, this removal is accomplished by the system of closed formations, known as Virchow-Robin's perivascular spaces. It follows that any substance injected into the brain substance will be eliminated into the subarachnoid space probably without being assimilated by the ganglion cells. On the other hand, any appropriate substance injected into the subarachnoid space will be discharged, as Key and Retzius and Weed showed, through the arachnoid villi (pacchionian bodies) into the blood stream without reaching the brain substance at all.

\section{ABSENCE OF PHYSICLOGIC SUPPORT FOR INTRASPINAL THERAPY}

The practical conclusion is obvious; namely, that intraspinal therapy of cases in which especially the parenchyma of the brain is deeply involved, as in general paresis, has no physiologic support. In those cases in which the trouble is in the subarachnoid space itself, as in cerebrospinal meningitis, the injection is wholly justified, for given in suitable doses it may produce results. But as used in intraspinal therapy, in very small doses (fractions of a grain of arsphenamin), therapeutic results can hardly be expected. I believe that the favorable reports of the Swift-Ellis method of treatment by some reliable observers can be explained, not by the action of the intraspinal injections, but by that of the intravenous ones. Arsenic injected into the blood may reach the spinal fluid and the meninges, as demonstrated 
among others by G. W. Hall, ${ }^{6}$ while Tilney ${ }^{7}$ found the membranes stained with trypan blue after injecting it intravenously. The foregoing observations show that a drug injected into the veins may reach the meninges, and there is no object in trying to accomplish the same result by the intraspinal route.

One more point deserves attention and at least a brief discussion. It has been almost generally admitted, especially by French and English observers (Laignel-Lavastine, Carrier, Pierret, Wilkes and McEwen) that every meningitis is an encephalitis, that every inflammation of the pia is accompanied by inflammation of the brain tissue proper. This opinion has been shown to be erroneous by the histologic research work of Ranke, ${ }^{8}$ while the foregoing considerations relative to the connections of the meningeal spaces with those of the brain, as well as to the flow of the brain tissue fluids, decidedly favor Ranke's views. Cases of pure leptomeningitis are not accompanied by encephalitis. The superficial layers of the cortex may be invaded from the meninges by pathologic elements and exhibit some inflammatory phenomena, but the latter will spare the deeper strata of the brain as well as its smallest blood vessels. If the latter are also involved, we have an encephalitis which is independently caused like the meningitis by the same morbid agent. These considerations also apply to poliomyelitis in which the parenchymatous and interstitial changes in the spinal cord are associated with meningitis. To consider the former as a product of the latter, that is, to assert with Harbits and Scheel," for instance, that the pathologic changes of the spinal cord in poliomyelitis are caused by the leptomeningitis, is not in accord with the facts, for both the meningeal and spinal cord changes are due to one cause. Such, in brief, are some of the facts that can be more or less definitely established from histopathologic studies of suppurative conditions of the brain.

31 North State Street.

6. Hall, G. W.: Report before the Chicago Neurological Society, Feb. 19, 1920.

7. Tilney, Fred: Long Island M. J. 8:121, 1914; J. Nerv. \& Ment. Dis. 41: 454, 1914.

8. Ranke, Otto: Beiträge zu der Lehre von Meningitis Tuberculosa, Nissl's Arbeiten 2:334, 1908 .

9. Harbitz, F., and Scheel, O.: Pathologisch-Anatomische Untersuchungen iiber akute Poliomyelitis und verwandte Krankheiten, Christiania, 1907. 